\title{
Staining of Thin Peripheral Blood Smear with Modified Methanolic Extract of Hibiscus sabdariffa Calyx
}

\author{
Emmanuel Asuquo Etim ${ }^{1 *}$, Oziegbe Johnson Airen ${ }^{2}$ \\ ${ }^{1}$ Hematology Department, Federal Medical Centre Yola, Adamawa State, Nigeria \\ ${ }^{2}$ University of Benin health Center, Edo State, Nigeria
}

DOI: $10.36348 /$ sjbr.2020.v05i09.004

| Received: 09.11.2019 | Accepted: 16.11.2019 | Published: 28.09.2020

*Corresponding author: Emmanuel Asuquo Etim

\section{Abstract}

Background/Objective: Methanolic extract of Hibiscus sabdariffa extract usually produces a brilliant reddish liquid and it is believed that modification of this colored liquid may have good staining effect on thin blood smear. Therefore, this study aims to examine the staining effect of modified methanolic extract of Hibiscus sabdariffa calyx on thin peripheral blood smear in other to obtain surrogates hematological stains. Materials and methods: Dried calyx of Hibiscus sabdariffa was obtained commercially from Yola. The calyces were pulverized to fine powder and $10 \mathrm{~g}$ of the powder was soaked in $50 \mathrm{ml}$ of absolute methanol for 12 hours to obtain methanolic extract and thereafter, equal volume of both methanolic extract and methylene blue were mixed to obtain a modified methanolic extract. $\mathrm{pH}$ of modified extract was determined using $\mathrm{pH}$ meter. The modified methanolic extract was further used to stain thin peripheral blood smear. Results: Modified methanolic extract of Hibiscus sabdariffa calyx had pH of 7.1. The extract produces a poor staining effect on erythrocyte but gave a deep blue coloration on leucocytes, while the control stains such as field stain and Leishman stain produces a normal coloration on leucocytes and a dark pink coloration with normal pallor on erythrocyte. Conclusion: Modified methanolic extract of Hibiscus sabdariffa calyx has PH of 7.1 and produces a poor staining effect on erythrocyte but impacted a deep blue coloration on nuclear lobes of leucocytes microscopically. More research to get a modified concentration and a molar equilibrium of acidic and basic components in this extract is recommended.

Keywords: Thin Blood Smear, Hibiscus sabdariffa calyx.

Copyright @ 2020: This is an open-access article distributed under the terms of the Creative Commons Attribution license which permits unrestricted use, distribution, and reproduction in any medium for non-commercial use (NonCommercial, or CC-BY-NC) provided the original author and source are credited.

\section{INTRODUCTION}

Hibiscus sabdariffa also known as Roselle is a species of Hibiscus in the Malvaceae family. It is a flowering annual woody-based herb usually 22.5 meters tall and widely cultivated in both tropical and subtropical regions of the world including Nigeria. The fruit and calyx of Roselle is reddish at maturation and extract of dried calyx of Hibiscus sabdariffa is widely consumed as Zobo drink beverage in Nigeria due to it numerous health benefit as well as low degree of acute toxicity and high median lethal dose [1]. This plant has been known to add several health benefits to man for instance, Hibiscus sabdariffa have been reported to, improve immunity [2] and red blood cell production in mammals [3]. In addition, available medical literatures show that various extract of this plant reduces cholesterol [4], lipid [5], blood viscosity [6] and blood pressure [7]. Furthermore, this plant have also been known to have anti-hypertensive [8], antidiabetic [9], antioxidant $[10,11]$ antipyretic, anticancer, antiseptic [12] and hepatoprotective[13] activities. The main compounds found in calyx of Hibiscus sabdariffa are citric acid, malic acids, anthocyanins, flavonoids, glycosides[14] caffeic acid, polyphenolic acid, protocatechuic acid, catechin and gallocatechins [15]. The nutritional and medical importance of this plant is believed to be due to the present of these phytochemical compounds.

Methanolic extract of this plant usually has a reddish coloration and it is believed that the reddish coloration of raw and modified methanolic extract of this plant may have a staining effect on thin blood smear in medical laboratory practice but to our knowledge no research have been reported on the staining effect of extract of Hibiscus sabdariffa calyx on thin peripheral blood film and this was the impetus for this study.

Peripheral blood film is a highly informative hematological tool for diagnosis and monitoring of disease conditions [16]. Thin blood film is a thin layer 
of blood smeared on a glass microscope slide and thin blood smear is prepared from anticoagulated blood obtained from venipuncture or finger prick. Depending on the layer of blood smeared on the slide, blood smear could be thin (thin layer) or thick (thick layer) and blood smear are usually stained in such a way as to allow various blood cells to be visibly examined microscopically and thin blood film is usually examined to investigate hematological abnormalities. Examination of blood smear is also essential in the diagnosis and management of anemias. The staining and examination of blood smear is one of the oldest, most widely and frequently used procedure for clinical test in hematology laboratory globally. As it has been stated already, thin blood smear is usually stained with dyes to allow easy identification of blood cells and since its introduction in the late nineteenth century, some elements of blood staining procedure have changed and/or modified. The improvements in modern medical laboratory technology have enhanced the availability of good quality stains. But the effect and ability of Hibiscus sabdariffa extract to stain blood film is still not well known and documented, this study therefore aims to examine the staining effect of modified methanolic extract of this plant's calyx on peripheral blood films in other to get more surrogates for hematological stains.

\section{MATERIALS AND METHOD}

This study was carrying out at hematology department of Federal Medical Center Yola, Adamawa state in Northeastern Nigeria. Dried calyx of Hibiscus sabdariffa was obtain commercially from local market in Yola. The calyces were pulverized to fine powder and $10 \mathrm{~g}$ of the powder was soaked in $50 \mathrm{ml}$ of absolute methanol for 12 hours, the mixture was further filtered using filter paper (Whatman No. 1) to obtain methanolic extract. The $\mathrm{PH}$ of the extract was determined using PH meter and $10 \mathrm{ml}$ of the extract was added to $10 \mathrm{ml}$ of methylene blue to obtain a modified version of the methanolic extract which was further used to stain thin peripheral blood smear. The stained smear was further examined microscopically with Olympus light microscope and the microscopic appearance of erythrocyte and leucocyte stained with modified methanolic extract of Hibiscus sabdariffa calyx was compared with the erythrocyte and leucocyte which was stained with control stains such as Field and Leishman stain respectively using standard methods [17]. Peripheral blood smear was prepared using slide method [18, 17]. The microscopic appearance of the blood cells presented in this study was gotten from the $\mathrm{X} 100$ objective lens of Olympus light microscope.

\section{Procedure for staining with modified methanolic extract of hibiscus sabdariffa calyx}

- Thin blood smear was prepared using the slide method [18, 17]

- The thin blood smear was allowed to air dried.
- The thin blood smear was further fixed in absolute methanol for 3 seconds and allowed to air dried.

- The dried thin blood smear was then flooded with modified methanolic extract of Hibiscus sabdariffa calyx.

- The flooded smear was allowed to stand for 20minutes.

- The smear was rinsed with four drops of distilled water and allow to air dry.

- And the stained smear was examined microscopically.

\section{RESULTS}

Addition of $10 \mathrm{~g}$ of Hibiscus sabdariffa calyx powder to $50 \mathrm{ml}$ of absolute methanol produces a brilliant reddish colored solution and this brilliant reddish coloration disappeared after addition of equal volume of methylene blue. The $\mathrm{pH}$ test of the solution shows that modified methanolic extract of Hibiscus sabdariffa calyx have a pH of 7.1 unlike raw methanolic extract which had a $\mathrm{pH}$ of 1.0. The microscopic appearance of stained red blood cell was examined and shown in figures in the main text. Figure 1 shows the microscopic appearance of red blood prior to staining while figure 2 shows microscopic appearance of red blood cell and white blood cell after being stained with modified methanolic extract of Hibiscus sabdariffa calyx. Figure 3 and 4 shows the microscopic appearance of red blood cell and white blood cells after being stained with Field and Leishman stain respectively.

The modified methanolic extract of Hibiscus sabdariffa calyx had a unique poor staining effect on red blood cell but produces a deep blue coloration on white blood cells microscopically. While the staining of thin peripheral blood smear with Field stain and Leishman stain produces normal coloration on leucocytes and a dark pink coloration on erythrocyte as in figure 3 and 4.

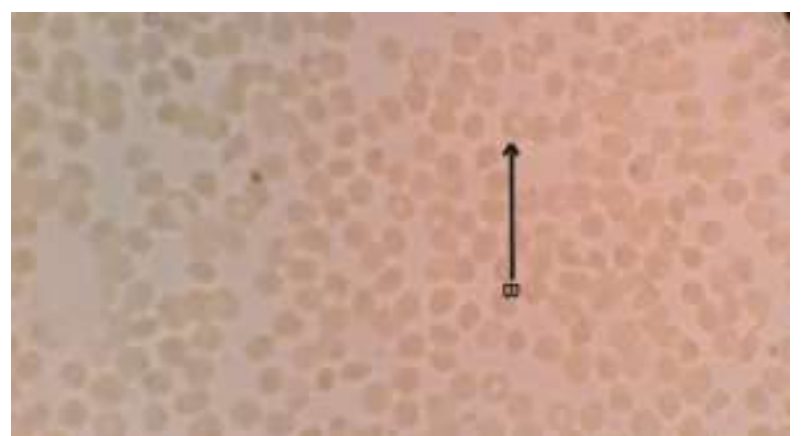

Fig-1: Unstained thin blood film showing arrow on unstained red blood cell (B) 


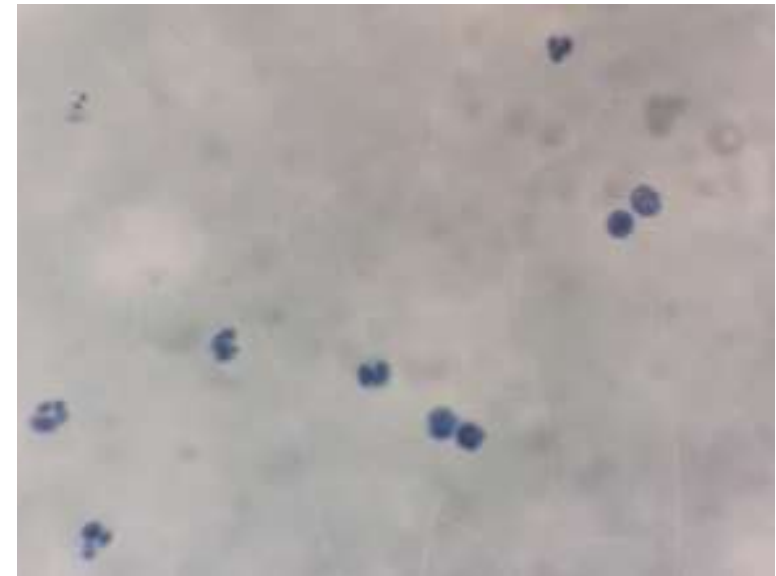

Fig-2: Thin blood film stained with modified methanolic extract of Hibiscus sabdariffa calyx showing arrow on stained red cell with pseudo large pallor

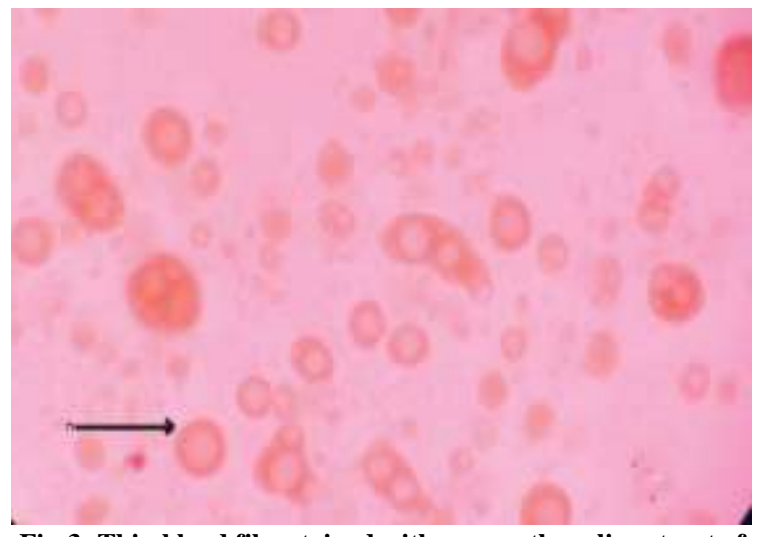

Fig-3: Thin blood film stained with raw methanolic extract of Hibiscus sabdariffa calyx showing arrow on stained red cell with pseudo large pallor

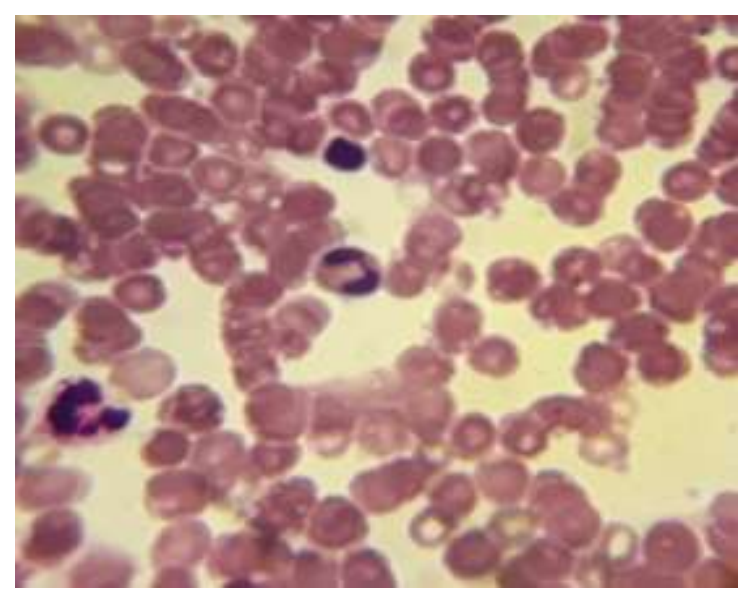

Fig-4: Thin Peripheral Blood Film Stain with Field Stain

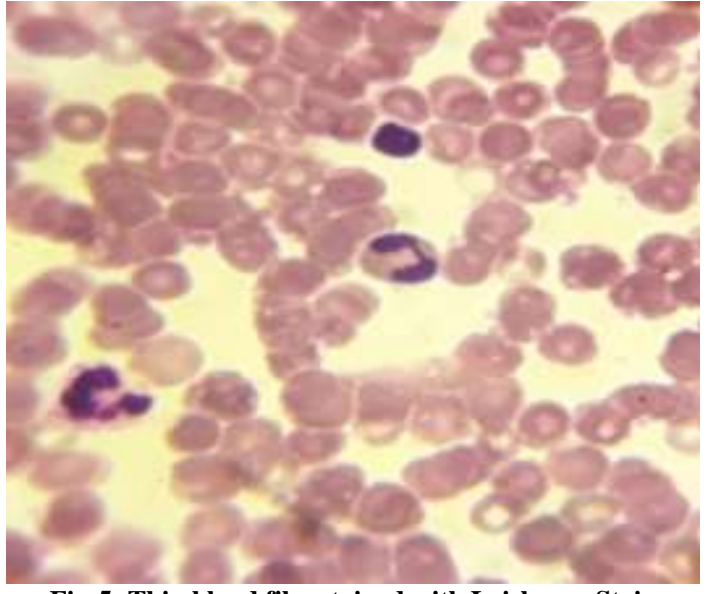

Fig-5: Thin blood film stained with Leishman Stain

\section{DISCUSION}

The staining effect of modified methanolic extract of Hibiscus sabdariffa calyx has been examined. In this study it was observed that the modified methanolic extract of this plant's calyx had a $\mathrm{pH}$ of 7.1 unlike the of raw methanolic extract of this plant's calyx which usually have a $\mathrm{pH}$ of 1.0). The modified methanolic extract of Hibiscus sabdariffa calyx had a unique poor staining effect on red blood cell and although there are a number of causes of variation in staining effect of various substances on blood cells but, the reason for the poor coloration produce on red blood cell by modified methanolic extract of this plant's calyx remains unclear and in addition, the mechanism by which certain cellular component will pick a particular stain depends on complex differences in binding ability as well as the nature of acidic and basic chemical component of such stain and a basic substance do bind to anionic molecules and acidic substance usually bind to cationic molecules on cells and since mature red blood cell content is mostly hemoglobin and hemoglobin usually picks up acidophilic component of stains [17], the presence of basic grouping on the hemoglobin molecule resulted in its affinity for acidic compounds which may be annulled by the addition of methylene blue in the modified version of the stain hence the poor staining effect on RBC by the modified version of stain unlike the raw methanolic extract of this plant's calyx when compare to the effect of Field and Lieshman stains on thin film.

On the other hand, the modified extract of this plant was able to produce a deep blue coloration on white blood cell because unlike RBC, WBC do contain more cytoplasmic organelles that can pick up methylene blue from the stain to produce a deep coloration visible on light microscope and it is believed that, the presence of basic substances in modified methanolic extract of Hibiscus sabdariffa calyx could be responsible for of staining effect on nucleated peripheral blood cells because acidic substances do have a poor staining effect on cell nucleus[17] and the staining effect of this extract can also be due to an alkaline $\mathrm{PH}$ which usually 
accentuates the azure (oxidized basic) component of stains at the expense of acidic components and vice versa hence the presence of methylene blue altered the staining effect of raw methanolic extract of this plant and produces a deep blue coloration on leucocytes.

Generally, a good staining effect on blood cell is obtained when there is a molar equilibrium between acidic and basic components of stains and this equilibrium may be absent in the modified version of methanolic extract of Hibiscus sabdariffa calyx but presence in Leishman and Field stain [19] hence, this extract could not produce a good staining of red blood cells unlike other conventional routine hematological stains.

\section{Disclaimer}

The views expressed in this article are that of the authors not an official position of any hospital or institution.

\section{Financial Sponsorship}

The study was not sponsored, the equipment used was provided by the hospital in which this work was done.

\section{ACKNOWLEDGEMENT}

The authors are sincerely grateful to the management of Federal Medical Center Yola, for providing the environment and equipment for this research work.

\section{Previous Publication}

This article has not been submitted to any journal except the one being considered now.

\section{Conflict of Interest}

There is no conflict of interest regarding this work among the authors.

\section{CONCLUSION}

From this present study, it was observed that, modified methanolic extract of Hibiscus sabdariffa calyx had PH of 7.1. The modified methanolic extract of Hibiscus sabdariffa calyx had a poor staining effect on red blood cell but impacted a deep blue coloration on nuclear lobes of leucocytes microscopically. More research to get a modified concentration and a molar equilibrium of acidic and basic components in this extract is recommended in other to obtain a better cost effective surrogate for good hematological stains in the medical laboratory practice.

\section{REFERENCES}

1. Ndu, O. O., Nworu, C. S., Ehiemere, C. O., Ndukwe, N. C., \& Ochiogu, I. S. (2011). Herbdrug interaction between the extract of Hibiscus sabdariffa L. and hydrochlorothiazide in experimental animals. Journal of medicinal food, 14(6), 640-644.
2. Archana, J. S., Paul, R., \& Tiwari, A. (2011). Indian Medicinal Plants: A rich source of natural immuno modulator. International Journal of Pharmacology, 7(2), 198-205.

3. Lubega, A., Bbosa, G. S., Musisi, N., Erume, J., \& Ogwal-Okeng, J. (2013). Effect of the total crude extracts of Hibiscus sabdariffa on the immune system in the Wistar albino rats.

4. Gurrola-Díaz, C.M., García-López, P.M., SánchezEnríquez, S., Troyo-Sanromán, R., AndradeGonzález, I., Gómez-Leyva, J.F. (2010). Effects of Hibiscus sabdariffa extract powder and preventive treatment (diet) on the lipid profiles of patients with metabolic syndrome. Phytomedicine, 17(7):500-505.

5. Kuriyan, R., Kumar, D. R., Rajendran, R., \& Kurpad, A. V. (2010). An evaluation of the hypolipidemic effect of an extract of Hibiscus Sabdariffa leaves in hyperlipidemic Indians: a double blind, placebo controlled trial. BMC complementary and alternative medicine, 10(1), 27.

6. Christian, K. R., Nair, M. G., \& Jackson, J. C. (2006). Antioxidant and cyclooxygenase inhibitory activity of sorrel (Hibiscus sabdariffa). Journal of Food Composition and Analysis, 19(8), 778-783.

7. Onyenekwe, P. C., Ajani, E. O., Ameh, D. A., \& Gamaniel, K. S. (1999). Antihypertensive effect of roselle (Hibiscus sabdariffa) calyx infusion in spontaneously hypertensive rats and a comparison of its toxicity with that in Wistar rats. Cell Biochemistry and Function: Cellular biochemistry and its modulation by active agents or disease, 17(3), 199-206.

8. Mohagheghi, A., Maghsoud, S., Khashayar, P., \& Ghazi-Khansari, M. (2010). The effect of Hibiscus sabdariffa on lipid profile, creatinine, and serum electrolytes: a randomized clinical trial. ISRN gastroenterology, 2011.

9. Mozaffari-Khosravi, H., Jalali-Khanabadi, B. A., Afkhami-Ardekani, M., \& Fatehi, F. (2009). Effects of sour tea (Hibiscus sabdariffa) on lipid profile and lipoproteins in patients with type II diabetes. The Journal of Alternative and Complementary Medicine, 15(8), 899-903.

10. Ochani, P. C., \& D’Mello, P. (2009). Antioxidant and antihyperlipidemic activity of Hibiscus sabdariffa Linn. leaves and calyces extracts in rats.

11. Christian, K. R., \& Jackson, J. C. (2009). Changes in total phenolic and monomeric anthocyanin composition and antioxidant activity of three varieties of sorrel (Hibiscus sabdariffa) during maturity. Journal of Food Composition and Analysis, 22(7-8), 663-667.

12. Emelike, C. U., \& Dapper, D. V. (2013). Effects of oral administration of aqueous extract of Hibiscus sabdariffa on some haematological parameters of Wistar albino rats. IOSR J. Dental Med. Sci, 9, 3134. 
13. Oshua, P. E., Ukegbu, C. Y., Eze, C., Nkwocha, C. C., Okafor, J. O., Amaechi, O., \& Ugochukwu, N. E. (2017). Biochemical effects of the aqueous extract of hibiscus sabdariffa on liver marker enzymes and lipid profiles in acetaminophenchallenged rats. Research Journal of Medicinal Plants, 11, 48-54.

14. Ali, B.H., Wabel, A.I., Blunden, G. (2005). Phytochemical, pharmacological and toxicological aspects of Hibiscus sabdariffa L.: a review. Phytother Res, 19(5):369-75.

15. Yang, M.Y., Peng, C.H., Chan, K.C., Yang, Y.S., Huang, C.N, Wang, C.J. (2010). The hypolipidemic effect of Hibiscus sabdariffa polyphenols via inhibiting lipogenesis and promoting hepatic lipid clearance. J Agric Food Chem, 58(2):850-859.

16. Adewoyin, A.S., Nwogoh, B. (2014). Peripheral Blood Film - A Review. Ann Ibd Pg med, 12(2):71-79.

17. Tkachuk, D.C., Hirschmann, J.V. (2007). Approach to the microscopic evaluation of blood and bone marrow. In: Wintrobe Atlas of Clinical Haematology. Lippincott: Williams \& Wilkins.

18. Ankur, P. (2015). Preparation of blood smears with different staining methods. https://www.slideshare.net/ankur16491/bloodsmear-staining.

19. General, S. (2005). In: Barrie Sims. The science of laboratory diagnosis. 2nd Ed. 